\title{
Expression and purification of recombinant ATF-mellitin, a new type fusion protein targeting ovarian cancer cells, in $P$. pastoris
}

\author{
MANMAN SU ${ }^{1,2}$, WEIQIN CHANG ${ }^{1}, \mathrm{KUN} \mathrm{ZHANG}^{1}$, MANHUA CUI $^{1}$, SHUYING WU $^{1}$ and TIANMIN XU ${ }^{1}$ \\ ${ }^{1}$ Department of Obstetrics and Gynecology, The Second Hospital, Jilin University, Changchun, Jilin 130041; \\ ${ }^{2}$ Department of Regenerative Medicine, College of Pharmacy, Jilin University, Changchun, Jilin 130021, P.R. China
}

Received August 4, 2015; Accepted September 22, 2015

DOI: $10.3892 /$ or.2015.4448

\begin{abstract}
Melittin is well known to possess cytolytic activity with wide-spectrum lytic properties and its potential use as an agent to treat several types of cancer has been tested. Due to the non-specific toxicity, melittin can impair not only cancer cells but also normal tissue. Thus, tumor-targeted toxins may be helpful for developing novel anticancer therapeutics. The urokinase-type plasminogen activator (uPA) plays a central role in tissue remodelling events occurring in normal physiology and in pathophysiology, including cancer invasion and metastasis. Heartening findings showed that uPA receptor is predominantly expressed on many types of cancer. Therefore, the amino-terminal fragment (ATF) of uPA which was able to identify and bond with cancer cells was used as the cell-targeting domain to make up tumor-targeted toxin in this study. In the present study, pPICZ $\alpha \mathrm{C}$-ATF-melittin eukaryotic expression vector was successfully constructed. After transformed into P. pastoris and induced by methanol, rATF-mellitin was detected by SDS-PAGE and western blot
\end{abstract}

Correspondence to: Professor Tianmin Xu, Department of Obstetrics and Gynecology, The Second Hospital, Jilin University, 218 Zi Qiang Street, Changchun, Jilin 130041, P.R. China

E-mail: tianminxu@aliyun.com

Abbreviations: ATF, amino-terminal fragment; BMGY, buffered minimal glycerol-complex medium; BMMY, buffered minimal methanol-complex medium; CCK-8, Cell Counting Kit-8; DO, dissolved oxygen level; ECM, extracellular matrix; EGF-domain, epidermal growth factor-like domain; ELISA, enzyme-linked immunosorbent assay; FBS, fetal bovine serum; GPI, glycosylphosphatidylinositol; rATF-mellitin, recombinant amino-terminal fragment-melittin; RT, reverse transcription; OPD, ortho-phenylenediamine; pBs, plasmid bluescript II; PBS, phosphate-buffered saline; RT, reverse transcription; TBST, Trisbuffered saline Tween-20; TFA, trifluoroacetic acid; uPA, urokinase plasminogen activator; uPAR, urokinase plasminogen activator receptor; YPD, yeast extract peptone dextrose

Key words: urokinase plasminogen activator, melittin, $P$. pastoris, ovarian cancer, fusion protein analysis. After induction with methanol, the expression level of rATF-mellitin was $312 \mathrm{mg} / \mathrm{l}$ in 80-1 fermentor. rATF-mellitin was purified to $>95 \%$ purity using SP Sepharose ion exchange chromatography and source ${ }^{\mathrm{TM}} 30 \mathrm{RPC}$ with $67.2 \%$ recovery. Cell proliferation assay showed that rATF-melittin inhibited growth of SKOV3 cells and had no cytotoxicity effect on normal cells. For the first time, we established a stable and effective rATF-mellitin P. pastoris expression system to obtain a high level of expression of secreted rATF-mellitin which was purified by a highly efficient purification procedure.

\section{Introduction}

Melittin which constitutes 40-60\% of dry whole honeybee venom is the most abundant component of whole bee venom (1). This amphipathic peptide of 26 residues contains a hydrophobic stretch of 19 amino acids followed by a cluster of 4 positively charged residues at the $\mathrm{C}$ terminus (2). Although it is a small peptide, melittin exhibits a variety of effects such as anti-inflammatory, anti-arthritic and anti-virus effects and pain-relieving effects in various cell types $(1,3,4)$. It also induces cell cycle arrest, growth inhibition and apoptosis in various tumor cells. Its potential use as an agent to treat hepatocellular carcinoma, breast, ovarian and prostate cancer has been tested in vivo or in vitro, with positive outcomes (5-8). Due to the non-specific toxicity, melittin can impair not only cancer cells but also normal tissue. Therefore, many approaches, such as, preparing nanoparticle or recombinant immunotoxin were developed in recent years to make melittin exhibit specific toxicity towards target cells (9-11).

The urokinase-type plasminogen activator (uPA) which is an extracellular serine protease plays a central role in tissue remodelling events occurring in normal physiology and in pathophysiology, including cancer invasion and metastasis. uPA consists of an epidermal growth factor-like domain (EGF-domain; residues 5-46) and a kringle domain (residues 50-131), which together comprise the amino-terminal fragment (ATF), followed by an interdomain linker (residues 132-147), and the catalytic domain (residues 148-411) (12). Its binding to the cell surface receptor (the urokinase-type plasminogen activator receptor, uPAR) via ATF renders it more accessible to plasminogen on the cell surface (13). Active 
uPA cleaves inactive plasminogen to generate active plasmin, a broad-specific serine protease, which can degrade a variety of extracellular matrix (ECM) proteins.

UPAR is predominantly expressed on inflammatory cells (14) and many types of cancer, including gastric, colon, breast and ovarian cancers, and cholangiocarcinoma in areas of cancer invasion and metastasis and low levels of UPAR are associated with a better survival (15-18). Moreover, prevention of uPA from binding to uPAR decreases invasion (12). uPA and UPAR are involved in ECM degradation, cancer invasion and metastasis by regulating the plasminogen/plasmin system (19). Thus, uPA-uPAR systems could be an ideal candidate for targeted cancer therapy.

A number of small molecule uPA inhibitors have been developed (20), however, most of these inhibitors lack sufficiently documented specificity (21). Moreover, ATF of uPA was studied as antagonist inhibitor by competing with uPA for binding to tumor cell surfaces (22). It efficiently inhibited the proliferation, migration and invasiveness of cancer cells in vitro and inhibited tumor invasion in vitro (13).

In the present study, we attempted to prepare a type of fusion protein, which could take advantage of anticancer effects of mellitin and could make use of the specific binding of ATF to upregulated UPAR on tumor surfaces as targeted part of fusion protein at the same time, and apply it to effective targeted treatment. Thereby, recombinant ATF-mellitin (rATF-mellitin) which contains amino acid sequences of ATF and melittin was expressed in P.pastoris and its anticancer effects were detected in vitro after purification.

\section{Materials and methods}

Strains, vectors and reagents. T4 DNA ligase, Taq DNA polymerase, plasmid preparation kit, DNA and protein markers, and restrictive enzymes were purchased from Takara Co., Ltd. (Otsu, Japan). The P. pastoris X-33, E. coli XL blue, pPICZaC vector and zeocin antibiotic were obtained from Invitrogen (Carlsbad, CA, USA), and all primers were synthesized by Sangon Biotechnology Co., Ltd. (Shanghai, China). pPICZ $\alpha \mathrm{C}$ vector without cleavage Ste13 was reconstructed and kept by our laboratory. The murine anti-human urokinase monoclonal antibody was obtained from American Diagnostica Inc. (USA). PCR purification kit was purchased from Sangon Biotechnology Co., Ltd. SP Sepharose XL and Source ${ }^{\mathrm{TM} 30}$ RPC reversed phase hydrophobic chromatography were purchased from Pharmacia (Sweden). HBL100 human breast epithelial cell line and SKOV3 human ovarian cancer cell line were obtained from the type culture collection of the Chinese Academy of Sciences (Shanghai, China).

Yeast culture media. P. pastoris was grown in yeast extract peptone dextrose (YPD) (2\% peptone, $1 \%$ yeast extract and $2 \%$ dextrose) or buffered minimal glycerol-complex medium (BMGY) (0.1 M potassium phosphate, $2 \%$ peptone, $1 \%$ yeast extract, $1.34 \%$ YNB and $1 \%$ glycerol). Buffered minimal methanol-complex medium (BMMY) was used for protein induction $(0.1 \mathrm{M}$ potassium phosphate, $2 \%$ peptone, $1 \%$ yeast extract, $1.34 \%$ YNB and $0.5 \%$ methanol). YPD-zeocin plates (1\% yeast extract, $2 \%$ peptone, $2 \%$ dextrose, $2 \%$ agar and $0.1 \mathrm{~g} / \mathrm{l}$ zeocin) were used for selecting positive transformants.
Construction of recombinant vector $p P I C Z \alpha C-A T F$. The DNA that encodes 155-156 amino acids of uPA was SacII site (ccgcgg) which could be used to connect ATF with the DNA sequence of melittin. Thus, we attempted to acquire DNA that encodes uPA 1-156 amino acids that includes DNA sequence encoding ATF and interdomain linker. Total RNA was extracted from SKOV3 cells and was used as the template for reverse transcription (RT) reaction. RT reaction was carried out with the following parameters: $42^{\circ} \mathrm{C} 60 \mathrm{~min}$ for RT, and then $94^{\circ} \mathrm{C} 5$ min to inactivate AMV reverse transcriptase. Then the obtained cDNA was used as the template for further PCR to amplify the DNA of human uPA. The upstream primer was: 5'-GTT CCA TCG AAC TGT GAC TG-3' and the downstream primer was, 5'-GGT TCT CGA TGG TGG TGA AT-3'; the temperature of annealing was $50^{\circ} \mathrm{C}$ and the polymerase was Takara Ex Taq. The amplified DNA fragment was detected by electrophoresis on $1.0 \%$ agarose gel. The amplified human uPA DNA fragment was inserted into cloning vector pMD18T and the recombinant plasmid which contained correct sequence of UPA was used as template for another PCR. The primers were: 5'-AAT CTC GAG AAG AGA TCT AAC GAG CAC CAA GTT-3' (upstream primer), which contained the XhoI site and the Kex2 site, and 5'-AAT GAA TTC TCA AAT CTT AAA CCG CGG GCC TCA-3' (downstream primer), which contained the EcoRI site. The temperature of annealing was $60^{\circ} \mathrm{C}$ and the polymerase was Takara Ex Taq. The amplified DNA fragment was detected by electrophoresis on $1.0 \%$ agarose gel. The amplified DNA fragment that contains uPA 1-156 amino acids was digested with XhoI and $E c o$ RI, and were then inserted into the corresponding sites of the expression vector $\mathrm{pPICZ} \alpha \mathrm{C}$. The recombinant plasmid was transformed into the competent cells of Escherichia coli XL-Blue and the recombinant colonies were selected by zeocin $(25 \mu \mathrm{g} /$ $\mathrm{ml}$ ) resistance. Both the nucleotide sequences of the inserted DNA and flanking sequence were verified by sequencing with GenomeLab DTCS-Quick Start kit and CEQ 2000 DNA analysis system (Beckman, USA).

Construction of expression vector pPICZ $\alpha C$-ATF-melittin. The DNA that encodes 1-26 amino acids of melittin was synthesized according to its native amino acid sequences by Sangon Biotechnology Co., Ltd., and was inserted into plasmid pBluescript II (pBs). For the sake of insertion into pPICZ $\alpha \mathrm{C}-\mathrm{ATF}$ vector, the cohensive end of SacII was added to the $5^{\prime}$ end, whereas, termination codon and the cohensive end of EcoRI were added to the $3^{\prime}$ end. In order to improve the yield of fusion protein, synonymous codons were replaced by yeast biased codons. The full length DNA sequence which we designed to insert into pPICZaC-ATF was as follows: 5'-GG TTC AAG ATT GGT GCT GTT TTG AAG GTT TTG ACT ACT GGT TTG CCA GCT TTG ATT TCT TGG ATT AAG AGA AAG AGA CAA CAA TGA G-3'; complementary strand, 5'-AA TTC TCA TTG TTG TCT CTT TCT CTT AAT CCA AGA AAT CAA AGC TGG CAA ACC AGT AGT CAA AAC CTT CAA AAC AGC ACC AAT CTT GAA CCG C-3'. Annealing was performed as follows: $6 \mu 10.5 \mathrm{mmol}$ $\mathrm{NaCl}$ and $25 \mu \mathrm{mol}$ single strand DNA were mixed. Then the compound was boiled for $3 \mathrm{~min}$ at $80^{\circ} \mathrm{C}$ and cooled down to room temperature gradually. After being annealed, the complementary strands contained cohesive end of SacII at the 
5 ' end, whereas, termination codon and the cohensive end of EcoRI were added at the $3^{\prime}$ end.

The recombinant plasmid pPICZ $\alpha \mathrm{C}$-ATF was digested with SacII and EcoRI, and then the annealed DNA sequence that encodes melittin was inserted into the corresponding sites of pPICZ $\alpha \mathrm{C}$-ATF vector. Then the recombinant plasmid was transformed into competent cells of Escherichia coli XL-Blue and the recombinant colonies were selected by zeocin $(25 \mu \mathrm{g} / \mathrm{ml})$ resistance. The positive clones were incubated in LB liquid medium for $12 \mathrm{~h}$, respectively, and the plasmids were extracted by plasmid preparation kit. Both the nucleotide sequences of the inserted DNA and flanking sequence were verified by sequencing with GenomeLab DTCS-Quick Start kit and CEQ 2000 DNA analysis system.

Transformation of $P$. pastoris and selection of high-level expression colonies. Plasmid DNA pPICZ $\alpha$ C-ATF-melittin was linearized with $S a c I$ and introduced into competent cells of $P$. pastoris X-33 strain by electroporation using a MicroPulser (Bio-Rad, USA) according to the pPICZa vector manual. After the electroporation, $1 \mathrm{M}$ ice-cold sorbitol was added immediately, and the cuvette contents were incubated at $30^{\circ} \mathrm{C}$ for $60 \mathrm{~min}$. The mixture was spread on yeast extract peptone dextrose (YPD) agar plates containing zeocin and cultured at $30^{\circ} \mathrm{C}$ for 2 days. Antibiotic zeocin was used in the concentration of $0.1 \mathrm{~g} / \mathrm{l}$. The blank plasmid of $\mathrm{pPICZ} \alpha \mathrm{C}$ was also transformed as a negative control.

After the transformants with zeocin resistance appeared, some transformants were randomly picked from the plates and initially cultured in a 50-ml conical tube containing $10 \mathrm{ml}$ BMGY medium at $28^{\circ} \mathrm{C}$ with shaking at $225 \mathrm{rpm}$ for $24 \mathrm{~h}$. The culture media $(0.5 \mathrm{ml})$ was sampled, respectively, centrifuged at $4^{\circ} \mathrm{C}, 10,000 \mathrm{rpm}$ for $5 \mathrm{~min}$, and the cell pellets were used for genomic DNA analysis. The yeast genomic DNA was extracted and PCR identification was carried out to select $P$. pastoris $\mathrm{X}-33$ strain which was the transformed recombinant plasmid. The primers were: 5-GAC TGG TTC CAA TTG ACA AGC-3' (upstream primer) and 5-ATC GAT CTC ACA GTG TTG ACC-3' (downstream primer). The temperature of annealing was $52^{\circ} \mathrm{C}$ and the polymerase was Takara Ex Taq.

The rest of the culture media were then centrifuged and cell pellets were resuspended in $10 \mathrm{ml} \mathrm{BMMY}$ medium to induce expression for 7 days. Methanol was added every $24 \mathrm{~h}$ to a final concentration of $0.5 \%(\mathrm{v} / \mathrm{v})$ for inducing the expression of the target protein. The culture media $(0.5 \mathrm{ml})$ were sampled per day and centrifuged at $4^{\circ} \mathrm{C}, 10,000 \mathrm{rpm}$ for $5 \mathrm{~min}$. The supernatant was used for recombinant protein detection and selection of high-level expression colonies.

SDS-PAGE and western blot assays. SDS-PAGE analysis was performed using a $12 \%$ gel. For western blot analysis, proteins in the gel were transferred to polyvinylidene fluoride membrane. The membrane was blocked with $5 \%$ non-fat milk powder which was dissolved in Tris-buffered saline Tween-20 (TBST) for $1 \mathrm{~h}$ and then incubated with the murine anti-human urokinase monoclonal antibody for $12 \mathrm{~h}$ at $4^{\circ} \mathrm{C}$. After being washed by TBST, the membrane was incubated with the goat anti-mouse IgG conjugated to HRP (Abclonal, USA), diluted to 1:2,000. The bound antibody was detected using EasyBlot ECL kit (Beyotime, China).
Optimized expression of rATF-melittin in P. pastoris. In order to achieve high level expression of rATF-melittin, different culture parameters including $\mathrm{pH}$ value and induction time were evaluated in the expression procedure. The $\mathrm{pH}$ values were adjusted to 3.5-7.5 with 0.5 intervals. High-level expression cell colony was cultured with the above processes as and the $\mathrm{pH}$ values were adjusted every day with disodium hydrogen phosphate and citric acid. At the desired time points, $0.5 \mathrm{ml}$ cell aliquots were withdrawn, and were then replaced with equal amount of fresh medium. The supernatant samples were used for enzyme-linked immunosorbent assay (ELISA).

ELISA. Individual wells of ELISA plate (Costar, USA) were coated with $50 \mu$ l supernatant sample of rATF-melittin which had been diluted with $50 \mu \mathrm{l}$ coating buffer $\left(15 \mathrm{mM} \mathrm{Na}_{2} \mathrm{CO}_{3}\right.$, $35 \mathrm{mM} \mathrm{NaHCO}, \mathrm{pH} 9.6)$ overnight at $4^{\circ} \mathrm{C}$. The plates were blocked with $5 \%(\mathrm{w} / \mathrm{v})$ non-fat milk powder in TBST and were incubated for $2 \mathrm{~h}$ at room temperature. The murine anti-human urokinase monoclonal antibody (American Diagnostica Inc.) was used at $1: 1,000$, incubated for $1 \mathrm{~h}$ at $37^{\circ} \mathrm{C}$. Following several washes with TBST, the plates were again incubated with goat anti-mouse IgG conjugated to HRP (Abclonal) (1:2,000 dilution with blocking buffer) for $1 \mathrm{~h}$. The color reaction was developed by addition of the substrate solution ortho-phenylenediamine (OPD) and incubated for $5 \mathrm{~min}$ at room temperature in the dark. Then $50 \mu \mathrm{l}$ stop solution $\left(2 \mathrm{M} \mathrm{H}_{2} \mathrm{SO}_{4}\right)$ was added to each well. The absorbance values at $490 \mathrm{~nm}$ were read in ELx800 microplate reader (Bio-Tek, USA) within $2 \mathrm{~h}$.

Large-scale expression of rATF-melittin. The highest-level expression transformant was cultured in a 5-1 shake flask containing $21 \mathrm{BMGY}$ medium at $28^{\circ} \mathrm{C}$ until the culture reached OD $600=6.0$. The shake flask culture was used to inoculate an 80-1 NBS BioFlo 5000 fermentor (New Brunswick Scientific, USA) containing 401 of fermentation basal salts medium FM 21 supplemented with PTM1 trace salts $(1.1 \mathrm{ml}$ of stock solution/l) and biotin ( $0.4 \mathrm{ml}$ of the stock solution/l). The dissolved oxygen level (DO) was set at $30 \%$ and the stirring rate was $700 \mathrm{rpm}$. The $\mathrm{pH}$ of the medium was maintained 6.5 by automatic addition of $5 \mathrm{M} \mathrm{NH}_{4} \mathrm{OH}$ or $1 \mathrm{M}$ phosphoric acid. Antifoam (5\%) was delivered as required and temperature was maintained at $28^{\circ} \mathrm{C}$. Growth was divided into three phases designated as glycerol, glycerol-fed and methanol-fed batch phases. After complete consumption of glycerol in the medium, a glycerol fed-batch phase was initiated by addition of $50 \%$ glycerol [containing $1.2 \%(\mathrm{v} / \mathrm{v})$ of PTM1 trace salts] at a rate of $400 \mathrm{ml} / \mathrm{h}$. The glycerol feed was carried out until the cell wet weight reached $180 \mathrm{~g} / \mathrm{l}$. The third phase was initiated by addition of methanol which contained $1.2 \%(\mathrm{v} / \mathrm{v})$ of PTM1 trace salts after glycerol was exhausted. Methanol was initially added at $144 \mathrm{ml} / \mathrm{h}$ for $4 \mathrm{~h}$ to allow the culture adapt to growth with methanol, then methanol was gradually increased to $440 \mathrm{ml} / \mathrm{h}$. Sampling of the culture medium was performed at the end of each phase and every $3 \mathrm{~h}$ to analyze cells wet weight, optical density, and to measure rATF-melittin expression based on SDS-PAGE analysis (ELISA analysis).

Purification of rATF-melittin. The supernatant was collected by centrifugation at $15,000 \mathrm{rpm}$ for $10 \mathrm{~min}$ and was clarified with a $0.45-\mu \mathrm{m}$ cellulose membrane. After being diluted four 
times with $20 \mathrm{mM} \mathrm{NaAc-HAc}(\mathrm{pH} 4.0)$ buffer, the $\mathrm{pH}$ of the fermentation broth was adjusted to 4.0 with $1 \mathrm{M}$ acetate acid. A cation exchange chromatographic column $(20 \mathrm{ml}$; SP Sepharose XL, Sweden) was equilibrated with $20 \mathrm{mM}$ $\mathrm{NaAc}-\mathrm{HAc}(\mathrm{pH} 4.0)$ buffer. The supernatant was loaded onto the cation exchange chromatographic column at the rate of $0.5 \mathrm{ml} / \mathrm{min}$. Then the column was extensively washed with the same buffer at the rate of $1 \mathrm{ml} / \mathrm{min}$. The bound protein was eluted with a linear gradient of $0.1-1.0 \mathrm{M} \mathrm{NaCl}$ while the flow rate was maintained at the rate of $1 \mathrm{ml} / \mathrm{min}$. Protein elution was monitored by measuring the absorbance at $280 \mathrm{~nm}$ and identified by SDS-PAGE analysis. Column effluent containing rATF-melittin was collected and loaded onto a reverse phase column $(2.0 \times 15 \mathrm{~cm}$; Source 30; Sweden) which was equilibrated with $0.1 \%$ trifluoroacetic acid (TFA) for further purification. rATF-melittin was eluted using 50\% methanol that containing $0.1 \%$ TFA at the rate of $1 \mathrm{ml} / \mathrm{min}$ and monitored by measuring the UV absorbance at $280 \mathrm{~nm}$. Column effluent containing rATF-melittin was concentrated by vacuum distillation and freeze drying to remove methanol. The finally purified rATF-melittin was stored at $-80^{\circ} \mathrm{C}$ for further studies.

$N$-terminal amino acid sequence analysis. To determine the $\mathrm{N}$-terminal sequence, the purified rATF-melittin was electrophoresed on $12 \%$ SDS-PAGE gel and electroblotted on a PVDF membrane. After being blotted, the PVDF membrane was stained with Coomassie brilliant blue R250, and the rATF-melittin band was cut out and determined by automated Edman degradation performed on a model PPSQ-21A protein sequencer (Shimadzu, Japan).

Cytotoxicity assay of rATF-melittin. The cytotoxicity of rATF-melittin on normal cells was monitored with using Cell Counting Kit-8 (CCK-8) assay. Briefly, human epithelial cells HBL100 were maintained in RPMI-1640 with $10 \%$ fetal bovine serum (FBS; HyClone, USA) and $100 \mathrm{U} / \mathrm{ml}$ of penicillin/ streptomycin, at $37^{\circ} \mathrm{C}$ in humidified atmosphere containing $5 \% \mathrm{CO}_{2}$. HBL100 cells were seeded into 96-well plates containing complete medium at a density of $1 \times 10^{4}$ cells/well and incubated for $24 \mathrm{~h}$ followed by different doses of rATFmelittin. HBL100 cells were treated with RPMI-1640 (as control) and 7.5, 15, 30, 60 and $120 \mu \mathrm{g} / \mathrm{ml}$ rATF-melittin for $24 \mathrm{~h}$, respectively. Then the medium was replaced with $200 \mu \mathrm{l}$ of fresh culture medium and $20 \mu \mathrm{l}$ CCK- 8 solution was added to each well. After being incubated for $2 \mathrm{~h}$, the absorbance was detected at $490 \mathrm{~nm}$ using a microplate reader (Bio-Rad Instruments, USA).

Inhibition effects of rATF-melittin on proliferation of ovarian cancer cells. SKOV3 cells were maintained in H-DMEM with $10 \% \mathrm{FBS}$ and $100 \mathrm{U} / \mathrm{ml}$ of penicillin/streptomycin, at $37^{\circ} \mathrm{C}$ in humidified atmosphere containing $5 \% \mathrm{CO}_{2}$. To test the inhibition effects of rATF-melittin on proliferation of ovarian cancer cells, SKOV3 cells were seeded into 96-well plates at a density of $1 \times 10^{4}$ cells/well and were incubated for $24 \mathrm{~h}$ followed by different doses of rATF-melittin. SKOV3 cells were treated with H-DMEM (as control) and 7.5, 15, 30, 60 and $120 \mu \mathrm{g} / \mathrm{ml}$ rATF-melittin for $24 \mathrm{~h}$, respectively. CCK-8 assay was performed as above.

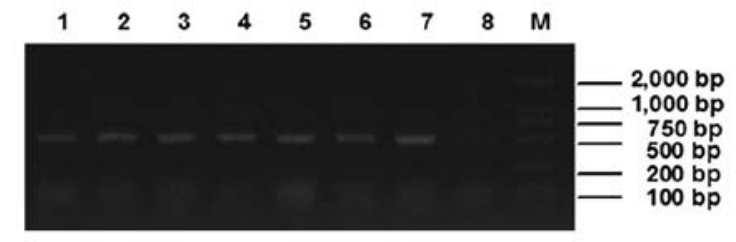

Figure 1. Agarose gel electrophoresis analysis of PCR product of the yeast genomic DNA. Lane M, DL 2000 marker (Takara). Lanes 1-7, PCR products of yeast genomic DNA transformed with pPICZ $\alpha \mathrm{C}$-ATF-melittin. Lane 8, PCR product of yeast genomic DNA transformed with pPICZ $\alpha \mathrm{C}$ blank plasmid.

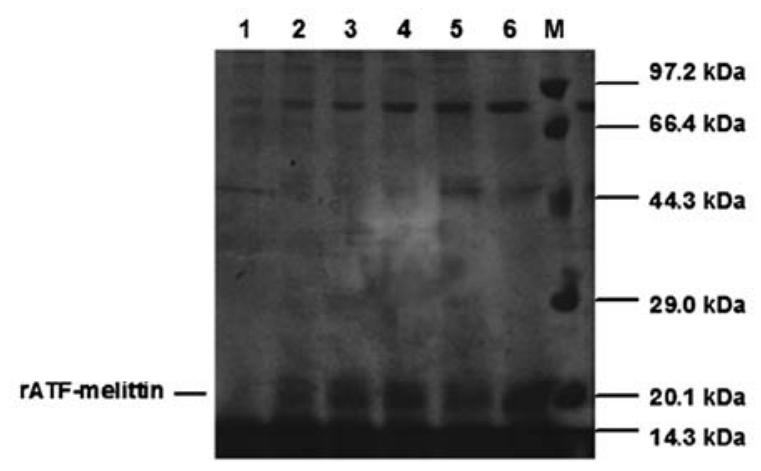

Figure 2. SDS-PAGE analysis of rATF-melittin. SDS-PAGE was performed on $12 \%$ gel and stained with coomassie brilliant blue. Lane M, protein molecular weight marker (low). Lane 1, supernatant from the negative stain transformed with pPICZ $\alpha$ blank plasmid. Lanes 2-6, supernatant from different rATF-melittin transformants after induction by methanol for $48 \mathrm{~h}$.

\section{Results}

Construction and transformation of pPICZ $\alpha C$-ATF-melittin. Results of DNA sequence analysis of the recombinant expression vector pPICZaC-ATF-melittin (data not shown) demonstrated that the DNA sequences encoding human uPA amino acids 1-156 and melittin were correctly inserted into pPICZ $\alpha \mathrm{C}$ vector and the amino acid sequence of ATF-melittin encoded was identical with that logged in GenBank.

After being cultured at $30^{\circ} \mathrm{C}$ for 2 days, dozens of transformants with zeocin resistance appeared on YPD agar plates which contained $0.1 \mathrm{~g} / 1$ zeocin. The PCR analysis of genomic DNA showed that the DNA sequence encoding human uPA amino acids 1-156 and melittin was indeed integrated into over $90 \%$ of clones which transformed with recombinant expression vector pPICZ $\alpha \mathrm{C}$-ATF-melittin. As the result showed (Fig. 1), there were $\sim 500 \mathrm{bp}$ amplification bands for the samples that were transformed with pPICZ $\alpha \mathrm{C}$-ATF-melittin, however, the control sample which was transformed with pPICZ $\alpha \mathrm{C}$ blank plasmid was negative.

Expression and detection of rATF-melittin in P. pastoris. After induction with methanol for rATF-melittin expression, the transformant which presented the highest expression level of rATF-melittin could be used for further experiments. SDS-PAGE analysis of rATF-melittin culture medium indicated rATF-melittin expressed after the inducing of methanol, however, the recombinant protein expression in the transformant containing blank plasmid of pPICZ $\alpha \mathrm{C}$ was negative. 
A

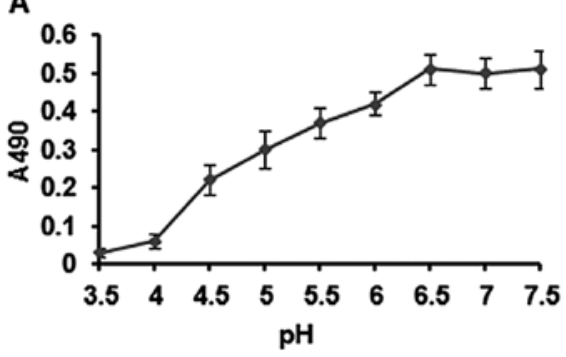

B

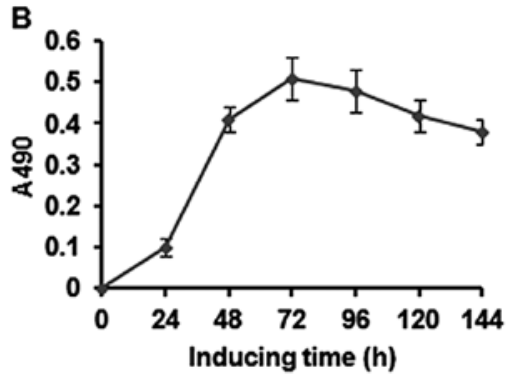

Figure 3. Optimized expression of recombinant human rATF-melittin in P.pastoris. (A) Optimization of the pH value. (B) Optimization of the methanol inducing time points. Supernatants collected at each evaluated condition were processed by ELISA analysis.
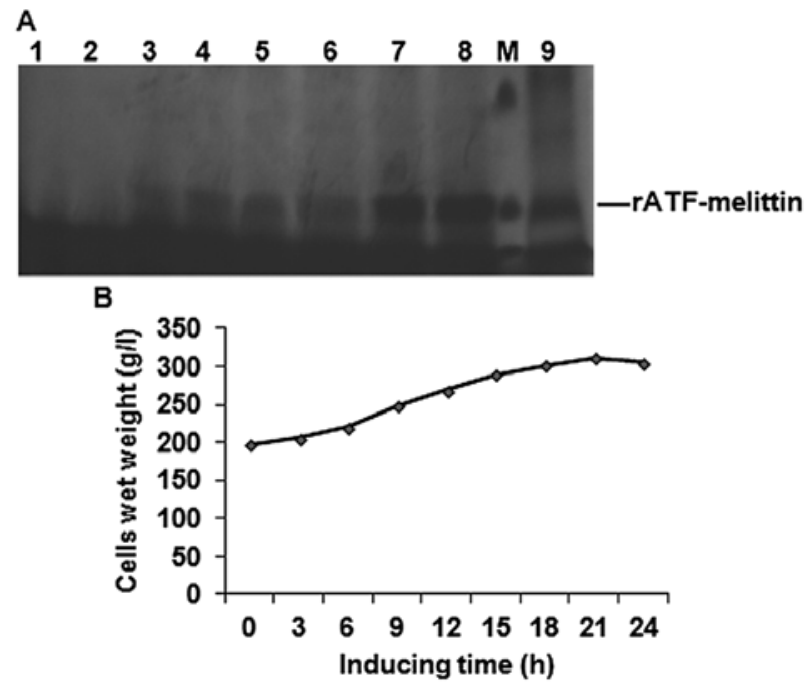

Figure 4. Large-scale expression of rATF-melittin. (A) SDS-PAGE analysis of supematant at different fermentation stage in 401 fermentation broth. Lanes 1-9, samples collected at different time after methanol inducing: 0,3, $6,9,12,15,18,2$ and $24 \mathrm{~h}$, respectively. Lane M, protein molecular weight marker (from up to down: 29 and $20.1 \mathrm{kDa}$ ). (B) Profile of $P$. pastoris growth at different times after methanol induction.

Based on the amino acids sequence, the calculated molecular weight of rATF-melittin was $20.9 \mathrm{kDa}$, which was consistent with the result of SDS-PAGE measurement (Fig. 2).

Optimized expression of rATF-melittin in P. pastoris. After a series of experiments, the optimal expression conditions of rATF-melittin were obtained as follows: the optimal $\mathrm{pH}$ was 6.5 (Fig. 3A) and the optimal induction time-point was about day 3 for the strain (Fig. 3B) at $28^{\circ} \mathrm{C}$ and with methanol daily addition concentration of $0.5 \%(\mathrm{v} / \mathrm{v})$ in $50-\mathrm{ml}$ tube. Under these conditions, the transformant of P. pastoris that presented the highest expression level was chosen for scaled-up protein production.

Large-scale expression and purification of rATF-melittin. The transformant which presented the highest-level expression was cultured to inoculate an 80-1 fermentor under the optimal fermentation conditions. Glycerol batch phase lasted $\sim 24 \mathrm{~h}$, and then $50 \%$ glycerol was added until the wet weight of culture cells reached $180 \mathrm{~g} / \mathrm{l}$. When glycerol was exhausted, OD value

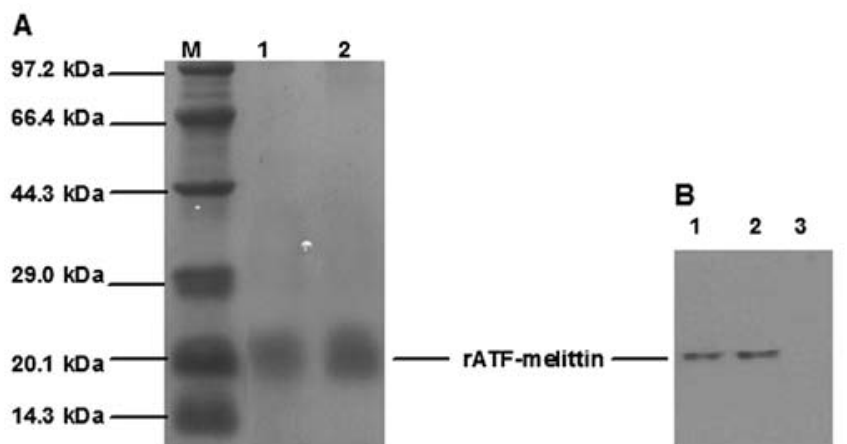

Figure 5. Purification and identification of rATF-melittin. (A) SDS-PAGE analysis of rATF-melittin lane $\mathrm{M}$, protein molecular weight marker. Lanes 1 and 2, purified rATF-melittin. (B) Western blot analysis. Lanes 1 and 2, purified rATF-melittin; lane 3, supernatant of rATF-melittin before adding methanol as a negative control.

abruptly increased. After being induced with methanol, samples were withdrawn every $3 \mathrm{~h}$ for SDS-PAGE analysis. The result indicated that during biomass generation phase, the carbon source (glycerol) only met the growth requirement of $P$. pastoris and there was no recombinant protein expression. Expression of rATF-melittin was initiated when methanol became the unique carbon source. After being induced for $18 \mathrm{~h}$, the transformant presented the highest expression level. The yield was not visibly changed between 18 and $24 \mathrm{~h}$ (Fig. 4).

Purification of rATF-melittin and characterization of purified rATF-melittin. The rATF-melittin supernatant was purified with a cation exchange chromatography and a reverse phase chromatography. Using an AKTA Explorer 100 chromatography system, we optimized the purification parameters. The optimal concentration of $\mathrm{NaCl}$ for elution was $0.5 \mathrm{M}$ and $50 \%$ methanol (containing $0.1 \%$ TFA) can elute the bound rATF-melittin from the reverse phase chromatographic column (Fig. 5A). After being purified, $5.19 \mathrm{~g}$ rATF-melittin was obtained from 401 fermentation broth. The concise purification protocol of rATF-melittin is presented in Table I.

The primary purified recombinant protein was identified by western blot analysis. The results demonstrated that the recombinant protein could bind with murine anti-human urokinase monoclonal antibody. No band was observed in lane 3 , which was the supernatant before adding methanol (Fig. 5B). 
Table I. Purification process of rATF-melittin.

\begin{tabular}{lcccc}
\hline $\begin{array}{l}\text { Purification } \\
\text { steps }\end{array}$ & $\begin{array}{c}\text { Total protein } \\
(\mathrm{g})\end{array}$ & $\begin{array}{r}\text { rATF-melittin } \\
(\mathrm{g})\end{array}$ & $\begin{array}{r}\text { Recovery } \\
(\%)\end{array}$ & $\begin{array}{c}\text { Purity } \\
(\%)\end{array}$ \\
\hline Supenatant & 12.48 & 7.74 & & 62 \\
SP Sepharose XL & 7.41 & 6.07 & 78.4 & 81.9 \\
Source $^{\mathrm{TM}}$ 30 RPC & 5.45 & 5.19 & 67.2 & 95.2 \\
\hline
\end{tabular}

ATF, amino-terminal fragment; rATF, recombinant ATF.

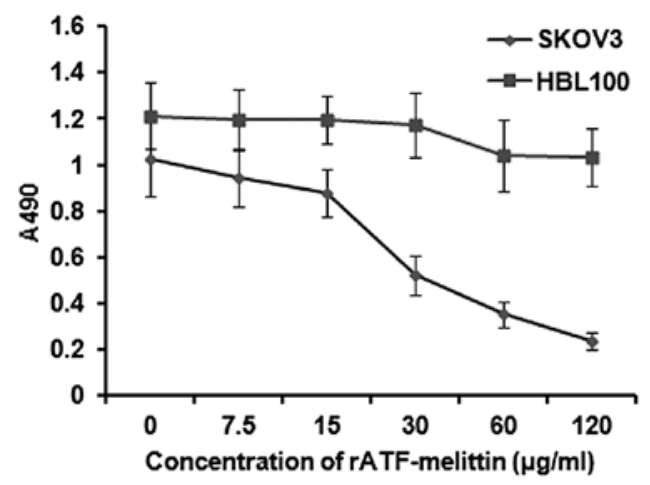

Figure 6. Effects of rATF-melittin on cell proliferation. Dose-effect curve of Inhibition effects of rATF-melittin on growth of ovarian cancer cells SKOV3 (diamonds); dose-effect curve of Inhibition effects of rATF-melittin on growth of human breast epithelial cells HBL100 (squares).

$\mathrm{N}$-terminal sequencing of rATF-melittin yielded the first 14 amino acids as S N E L H Q V P S N C D C L. The N-terminal sequence of rATF-melittin was identical to that of human uPA, confirming the successful expression and purification of rATF-melittin.

Anticancer effects of rATF-melittin. After being treated with rATF-melittin at different doses, some SKOV3 cells showed membrane blebbing, ballooning and chromatin condensation. However, the cells grew well with adherence and the cells were fusiform or diamond shaped in the control group CCK-8 assay was used to detect the quantity of cells. As a result, rATF-melittin treatment caused a dose-dependent inhibition of growth on SKOV3 at $24 \mathrm{~h}$. The inhibition rate is $\sim 80 \%$ at the dose of $120 \mu \mathrm{g} / \mathrm{ml}$. However, the result (Fig. 6) showed that rATF-melittin did not have much influence on the proliferation of normal cells (HBL100). The reason is that uPAR is highly expressed in ovarian cancer cells SKOV3, but it is undetectable in normal cells such as HBL100. In other words, the anticancer effect of rATF-melittin can be exerted when UPA combines with its receptor-uPAR followed by the release of melittin. Thus, the fusion protein expressed showed no obvious toxicity on normal tissues and can be applied to ovarian cancer targeted therapy.

\section{Discussion}

Ovarian cancer is the fourth leading cause of cancer mortality among women in Western societies (23). Patients with ovarian cancer have less than $50 \%$ chance of 5-year survival and a majority of patients die of disease recurrence or metastasis (24). In case of relapse, therapeutic options are limited, particularly if the relapse occurs within 6 months after completion of primary treatment (25). Consequently, it is clear that new treatments are necessary for ovarian cancer.

Melittin is well known to possess cytolytic activity with wide-spectrum lytic properties. Thus, we chose melittin as the cytotoxic agent to treat cancer cells. However, it is not only cytotoxic to tumors, but also vital to normal cells. It is crucial to control melittin to exhibit specific toxicity towards target cells and to reduce its toxicity towards normal tissue. Melittin had low toxicity when coupled with target peptides (26). Thus, tumor-targeted toxins may be helpful for developing novel anticancer therapeutics.

It has been shown that uPAR is predominantly expressed on many types of cancer, including gastric, colon, breast and ovarian cancers, and cholangiocarcinoma. In the present study, uPA was used as the cell-targeting domain to identify and bond with ovarian cancer cells. uPA was connected with melittin to construct the tumor-targeted toxins-rATF-mellitin. uPA was able to identify cancer cells and led melittin to bond with them, and then perform its lytic properties on the one hand, and on the other rATF-mellitin played a role as antagonist inhibitor by competing with native uPA by binding to tumor cell surfaces.

The present study focuses on expression of the targeted toxin rATF-mellitin, which can be used in ovarian cancer target therapy. In the present study, pPICZ $\alpha$ C-ATF-melittin eukaryotic expression vector was successfully constructed. After transformed into P. pastoris and induced by methanol, rATF-mellitin was detected by SDS-PAGE and western blot analysis. After induction with methanol, the expression level of rATF-mellitin was $312 \mathrm{mg} / \mathrm{l}$ in $80-1$ fermentor which contains 401 fermentation broth. rATF-mellitin was purified to $>95 \%$ purity using SP Sepharose ion exchange chromatography and source ${ }^{\mathrm{TM}} 30 \mathrm{RPC}$ with $67.2 \%$ recovery. Cell proliferation assay showed that rATF-melittin inhibited growth of SKOV3 cells and had no cytotoxicity effect on normal cells. For the first time, we established a stable and effective rATF-mellitin $P$. pastoris expression system to obtain a high level of expression of secreted rATF-mellitin, which was purified by a highly efficient and easy to handle purification procedure.

\section{Acknowledgements}

The present study was supported by grants from the National Natural Science Foundation of China (81272875, 30973187, 81401221 and 81302242), the Ministry of Education for Young Teacher Foundation of China (20110061120084), the Jilin Science and Technology Funds (20140520047JH, 20150204007YY, 20130102094JC and 20140204022YY), and the Basic Scientific Research of Jilin University Funds and Young Scholars Program of Norman Bethune Health Science Center of Jilin University (20142116).

\section{References}

1. Raghuraman $\mathrm{H}$ and Chattopadhyay A: Melittin: A membraneactive peptide with diverse functions. Biosci Rep 27: 189-223, 2007. 
2. Sommer A, Fries A, Cornelsen I, Speck N, Koch-Nolte F, Gimpl G, Andrä J, Bhakdi S and Reiss K: Melittin modulates keratinocyte function through $\mathrm{P} 2$ receptor-dependent ADAM activation. J Biol Chem 287: 23678-23689, 2012.

3. Son DJ, Lee JW, Lee YH, Song HS, Lee CK and Hong JT: Therapeutic application of anti-arthritis, pain-releasing, and anti-cancer effects of bee venom and its constituent compounds. Pharmacol Ther 115: 246-270, 2007.

4. Wang C, Chen T, Zhang N, Yang M, Li B, Lü X, Cao X and Ling C: Melittin, a major component of bee venom, sensitizes human hepatocellular carcinoma cells to tumor necrosis factorrelated apoptosis-inducing ligand (TRAIL)-induced apoptosis by activating CaMKII-TAK1-JNK/p38 and inhibiting IkappaBalpha kinase-NFkappaB. J Biol Chem 284: 3804-3813, 2009.

5. Jo M, Park MH, Kollipara PS, An BJ, Song HS, Han SB, Kim JH, Song MJ and Hong JT: Anti-cancer effect of bee venom toxin and melittin in ovarian cancer cells through induction of death receptors and inhibition of JAK2/STAT3 pathway. Toxicol Appl Pharmacol 258: 72-81, 2012.

6. Liu S, Yu M, He Y, Xiao L, Wang F, Song C, Sun S, Ling C and Xu Z: Melittin prevents liver cancer cell metastasis through inhibition of the Rac1-dependent pathway. Hepatology 47: 1964-1973, 2008.

7. Russell PJ, Hewish D, Carter T, Sterling-Levis K, Ow K, Hattarki M, Doughty L, Guthrie R, Shapira D, Molloy PL, et al: Cytotoxic properties of immunoconjugates containing melittinlike peptide 101 against prostate cancer: In vitro and in vivo studies. Cancer Immunol Immunother 53: 411-421, 2004.

8. Soman NR, Baldwin SL, Hu G, Marsh JN, Lanza GM, Heuser JE, Arbeit JM, Wickline SA and Schlesinger PH: Molecularly targeted nanocarriers deliver the cytolytic peptide melittin specifically to tumor cells in mice, reducing tumor growth. J Clin Invest 119: 2830-2842, 2009.

9. Moghadam BY, Hou WC, Corredor C, Westerhoff P and Posner JD: Role of nanoparticle surface functionality in the disruption of model cell membranes. Langmuir 28: 16318-16326, 2012.

10. Funayama JC, Pucca MB, Roncolato EC, Bertolini TB, Campos LB and Barbosa JE: Production of human antibody fragments binding to melittin and phospholipase A2 in Africanised bee venom: Minimising venom toxicity. Basic Clin Pharmacol Toxicol 110: 290-297, 2012.

11. Holle L, Song W, Holle E, Wei Y, Li J, Wagner TE and Yu X: In vitro- and in vivo-targeted tumor lysis by an MMP2 cleavable melittin-LAP fusion protein. Int J Oncol 35: 829-835, 2009.

12. Botkjaer KA, Deryugina EI, Dupont DM, Gårdsvoll H, Bekes EM, Thuesen CK, Chen Z, Ploug M, Quigley JP and Andreasen PA: Targeting tumor cell invasion and dissemination in vivo by an aptamer that inhibits urokinase-type plasminogen activator through a novel multifunctional mechanism. Mol Cancer Res 10 1532-1543, 2012.

13. Li J, Lin Y, Zhuang H and Hua ZC: Expression, purification, and biological characterization of the amino-terminal fragment of urokinase in Pichia pastoris. J Microbiol Biotechnol 23: 1197-1205, 2013.
14. Yang L, Sajja HK, Cao Z, Qian W, Bender L, Marcus AI, Lipowska M, Wood WC and Wang YA: uPAR-targeted optical imaging contrasts as theranostic agents for tumor margin detection. Theranostics 4: 106-118, 2013.

15. Ding Y, Zhang H, Zhong M, Zhou Z, Zhuang Z, Yin H, Wang X and Zhu Z: Clinical significance of the uPA system in gastric cancer with peritoneal metastasis. Eur J Med Res 18: 28, 2013.

16. Thummarati P, Wijitburaphat S, Prasopthum A, Menakongka A Sripa B, Tohtong R and Suthiphongchai T: High level of urokinase plasminogen activator contributes to cholangiocarcinoma invasion and metastasis. World J Gastroenterol 18: 244-250, 2012.

17. Foekens JA, Peters HA, Look MP, Portengen H, Schmitt M, Kramer MD, Brünner N, Jänicke F, Meijer-van Gelder ME, Henzen-Logmans SC, et al: The urokinase system of plasminogen activation and prognosis in 2780 breast cancer patients. Cancer Res 60: 636-643, 2000.

18. Kim TD, Song KS, Li G, Choi H, Park HD, Lim K, Hwang BD and Yoon WH: Activity and expression of urokinase-type plasminogen activator and matrix metalloproteinases in human colorectal cancer. BMC Cancer 6: 211, 2006.

19. Laufs S, Schumacher J and Allgayer H: Urokinase-receptor (u-PAR): an essential player in multiple games of cancer: a review on its role in tumor progression, invasion, metastasis, proliferation/dormancy, clinical outcome and minimal residual disease. Cell Cycle 5: 1760-1771, 2006.

20. Rockway TW, Nienaber V and Giranda VL: Inhibitors of the protease domain of urokinase-type plasminogen activator. Curr Pharm Des 8: 2541-2558, 2002.

21. Carriero MV and Stoppelli MP: The urokinase-type plasminogen activator and the generation of inhibitors of urokinase activity and signaling. Curr Pharm Des 17: 1944-1961, 2011.

22. Li H, Soria C, Griscelli F, Opolon P, Soria J, Yeh P, Legrand C, Vannier JP, Belin D, Perricaudet M, et al: Amino-terminal fragment of urokinase inhibits tumor cell invasion in vitro and in vivo: Respective contribution of the urokinase plasminogen activator receptor-dependent or-independent pathway. Hum Gene Ther 16: 1157-1167, 2005

23. Longuespée R, Boyon C, Desmons A, Vinatier D, Leblanc E, Farré I, Wisztorski M, Ly K, D'Anjou F, Day R, et al: Ovarian cancer molecular pathology. Cancer Metastasis Rev 31: 713-732, 2012.

24. Su D, Katsaros D, Xu S, Xu H, Gao Y, Biglia N, Feng J, Ying L, Zhang P, Benedetto C, et al: ADP-ribosylation factor-like 4C (ARL4C), a novel ovarian cancer metastasis suppressor, identified by integrated genomics. Am J Transl Res 7: 242-256, 2015.

25. Coosemans A, Baert T and Vergote I: A view on dendritic cell immunotherapy in ovarian cancer: How far have we come? Facts Views Vis Obgyn 7: 73-78, 2015.

26. Sun D, Sun M, Zhu W, Wang Z, Li Y and Ma J: The anti-cancer potency and mechanism of a novel tumor-activated fused toxin, DLM. Toxins 7: 423-438, 2015. 